\title{
Resurfacing on Venus
}

\author{
I. Romeo ${ }^{\mathrm{a}, *}$, D.L. Turcotte ${ }^{\mathrm{b}}$ \\ a Departamento de Geodinámica, Universidad Complutense de Madrid, C/José Antonio Novais 12, CP-28040 Madrid, Spain \\ ${ }^{b}$ Department of Geology, University of California Davis, One Shields Avenue, Davis, CA 95616-8605, USA
}

Keywords:

Resurfacing

Cratering

Planetary evolution

Venus

\begin{abstract}
A B S T R A C T
The resurfacing evolution of Venus has been evaluated through Monte Carlo simulations. For the first time, the sizes of volcanic flows in the models were generated using the frequency-size distribution of volcanic units measured on Venus. A non-homogeneous spatial generation of volcanic units was included in the models reproducing the Beta-Alta-Themis volcanic anomaly. Crater modification is simulated using a 3D approach. The final number of modified craters and randomness of the crater population were used to evaluate the success of the models, comparing the results from our simulations with Venus observations. The randomness of the crater population is evaluated using pair-correlation statistics. On the one hand, a catastrophic resurfacing event followed by moderate volcanic activity covering $\approx 40 \%$ of the planetary surface can reproduce the number of modified craters and the pair-correlation statistics do not reject randomness. On the other hand, the pair-correlation test for equilibrium steady-state resurfacing models rejects the randomness of the crater population when reproducing the observed frequency-size distribution of the volcanic units with a non-homogeneous spatial generation of volcanic units.
\end{abstract}

\section{Introduction}

The geologic evolution of Venus is still a controversial topic since high-resolution radar images obtained by the Magellan mission revealed a low global number of craters, $\approx 942$ (Herrick et al., 1997), with a spatial distribution that cannot be distinguished from a uniformly random distribution, and a small fraction of modified craters. These observations were interpreted as caused by a catastrophic event followed by a decay of the volcanic activity (Schaber et al., 1992; Strom et al., 1994) or an equilibrium steady-state evolution where the low number of craters is maintained through small-scale time-transgressive resurfacing events (Phillips et al., 1992; Hauck et al., 1998).

Detailed studies of the process of crater modification (Herrick and Sharpton, 2000; Wichman, 1999) revealed that the amount of craters partially covered by lava flows is higher than the initial estimation of 56 modified craters of Schaber et al. (1992). The updated version (third release) of the crater database initially published by Herrick et al. (1997) estimates the number of craters modified by volcanism to be between 85 and 129, while Wichman (1999) estimates this value to be between 57 and 123 (6-13\% of the crater population). These higher numbers of modified craters provided new support to equilibrium steady-state resurfacing

\footnotetext{
* Corresponding author. Tel.: + 34913944821; fax: +34913944845.

E-mail addresses: iromeobr@geo.ucm.es (I. Romeo) turcotte@geology.ucdavis.edu (D.L. Turcotte).
}

evolutions (Herrick and Sharpton, 2000; Stofan et al., 2005). In contrast, the analysis of craters modified by volcanism performed by Collins et al. (1999) provide that they are in the range 29-56, favoring a catastrophic scenario with a very limited volcanic activity since the global resurfacing event.

A wide variety of Monte Carlo simulations of the interaction between volcanic resurfacing and cratering on Venus has been performed. Phillips et al. (1992) used equal-sized volcanic units produced at constant generation rates without considering modified craters (all the craters touched by a volcanic unit were considered completely destroyed). Schaber et al. (1992) also used equal-sized volcanic units produced periodically at a constant time rate during the resurfacing process but added an estimation of the number of modified craters. They considered that a crater is modified when it is partially covered by the edge of a circular volcanic unit. Strom et al. (1994) performed Monte Carlo simulations of different equilibrium resurfacing evolutions with the same approach to the number of modified craters. Several models had equal-area volcanic units at constant intervals, and one model used the frequency-diameter distribution of volcanoes of Head et al. (1992) produced at constant intervals. A more realistic 3D approach for crater modification was achieved by Bullock et al. (1993) using a topographic grid, generating the volcanic units at constant rates. Hauck et al. (1998) studied the randomness of the Venusian crater population through the nearest neighbor analysis, demonstrating that it can be reproduced both by a catastrophic resurfacing event and also by more evolutionary models with different ages of generation of the 
volcanic plains, but this study did not take into account the number of modified craters. Kreslavsky (1996) modeled catastrophic and equilibrium resurfacing, estimating the number of modified crated using a 2D approach, concluding that very large plain units are incompatible with equilibrium resurfacing. Bond and Warner (2006) developed Monte Carlo simulations for equilibrium resurfacing using variable rates of volcanic activity with a decay in the size of the volcanic units, but with a fixed unit size for a given age in the model. Bjonnes et al. (2008) performed Monte Carlo simulations with a simple 2D approach for crater modification.

Despite the high quality data provided by the Magellan spacecraft, the discussion between catastrophic versus equilibrium resurfacing on Venus has continued for more than 10 years. This is because the ages of the units cannot be determined by crater densities and the frequency-size of the volcanic units on Venus was unconstrained. The size and the location of the volcanic units are the fundamental parameters that control spatial randomness of the crater population. Recently, the progress in detailed geological mapping performed by NASAUSGS, has revealed the sizes of volcanic units (Romeo and Turcotte, 2009), providing a major constraint on the possible resurfacing models for Venus.

The present work compares the observed randomness of the crater population, the number of modified craters and the measured frequency-size distribution of volcanic units with the results of Monte Carlo simulations reproducing both catastrophic and equilibrium geological evolutions of Venus. Monte Carlo simulations, even well advanced, cannot accurately imitate real resurfacing. They are very useful, however, to understand how the nature of resurfacing controls the observable properties of the crater population.

\section{Monte Carlo simulations}

Our Monte Carlo simulations generate an initially determined number of craters through a random process in space and time. The rim crater diameter is assigned following the frequency-size distribution of the Venusian craters. The 3D approach for crater modification, explained below, erases more effectively the small craters than the big ones. This produces a small distortion of the final frequency-size distribution of the craters. This small effect can be neglected considering the small percentage represented by the modified craters in the total population. The ejecta diameter is calculated using the continuous ejecta average extent power-laws for craters bigger and smaller than $20 \mathrm{~km}$ derived from the crater population by Herrick et al. (1997). The crater rim height is obtained from the power law relation deduced for bright-floored craters, which are considered to be pristine, calculated by Herrick and Sharpton (2000). The total number of craters generated is an indication of the duration of the models. The conversion from number of craters to time units was performed assuming that the average age of the Venusian surface is $750 \mathrm{Ma}$ (McKinnon et al., 1997). Assuming a different plausible average age from 300 to $850 \mathrm{Ma}$ would not change the results of this work, but only the duration represented by the models.

The modeling also generates a predetermined number of circular volcanic units with different ages. The frequency of occurrence of volcanic units follows an exponential decay with time. The time of emplacement of a unit is given by

$t=\frac{1}{-\kappa} \ln \left[p+e^{-\kappa}(1-p)\right]$

where $t$ is the dimensionless time from 0 to $1(t=0$ when model starts, $t=1$ when model ends) representing the age of a volcanic unit, $p$ is a random number picked between 0 and 1 , and $\kappa$ is a dimensionless parameter that controls how strong is the exponential decay (when $\kappa \rightarrow 0$ the distribution tends to be uniformly random in time). Eq. (1) was used for generating the ages of volcanic units using a random number generator for the value of $p$.

The spatial distribution of the volcanism during modeling is not uniformly random, reproducing the observed concentration of volcanic units in Beta-Alta-Themis region (BAT anomaly). The percentage of volcanoes inside the BAT anomaly is estimated to be $66 \%$ of the total population (Crumpler et al., 1997); consequently $66 \%$ of the volcanic units generated were located inside the BAT anomaly area and the rest outside, with spatial random distributions in each case. This differential spatial location of volcanic units is reproduced during the entire time span of the models. Although the origin of the BAT anomaly could be considered as generated only in the recent evolution of the planet, there is no significant difference in results if the model includes the BAT anomaly from the beginning or only at the final stage. This is because the resurfacing in this area is intense enough that the early evolution of this area is completely erased at the end of the model.

The sizes of volcanic units were generated following the frequency-size distribution observed in Venus. This frequencysize distribution was measured in two separated areas of the planet (Romeo and Turcotte, 2009) covering together $21.02 \%$ of the planetary surface.

The frequency-size distribution was measured on the $1: 5,000,000$ geological maps published by NASA/USGS, which are the best source for measuring sizes of volcanic units available. The cumulative frequency-area distribution of 1544 units covers 6 orders of magnitude from the largest unit $\left(30 \times 10^{6} \mathrm{~km}^{2}\right)$ to the smallest $\left(20 \mathrm{~km}^{2}\right)$. The volcanic units were measured on detailed geologic maps performed by a large number of geologists (McGill, 2004; Campbell and Campbell, 2002; McGill, 2000; Campbell and Clark, 2006; Copp and Guest, 2007; Bender et al., 2000; Ivanov and Head, 2004; Rosenberg and McGill, 2001; Ivanov and Head, 2005; Young and Hansen, 2003; Hansen and DeShon, 2003). The smallest units detected are restricted by resolution limits of the radar images and the scale of the geological mapping. Some units are mapped as flow fields, composed by a number of smaller individual volcanic flows that were not mapped. The units that made up those flow fields are grouped considering their similar characteristics, and are interpreted to be co-genetic. The effect of differences in age between individual flows inside a flow field can be neglected for a global scale resurfacing modeling. If the large units were made up by a number of flows of different ages the resultant resurfacing would produce a higher number of modified craters than predicted by the models.

Although some of the smallest volcanic units are out of the scale of the mapping and missed in the frequency-area distribution, sizes of the large and medium volcanic units are well constrained. The frequency-area distribution of the medium and large units is the main parameter that controls the evolution of the resurfacing models; therefore we consider our results confident.

The geometry of each unit in the model is a flat cone with an edge angle of $0.5^{\circ}$ following the approach of Romeo and Turcotte (2009). The morphometry data of large volcanoes from Herrick et al. (2005) allow calculation of the values of real slopes of large volcanoes on Venus ranging from $0.2^{\star}$ to $1.5^{\bullet}$, with an average of $0.63^{\circ}$ (Romeo and Turcotte, 2009). The edge angle of the large plains units not associated with a center of emission was determined to be about $0.5-1.0^{*}$ by Kreslavsky and Head (1999) using the morphometry of small shield volcanoes. Collins et al. (1999) used a slope of $0.5^{*}$ to model the embayment of the large 
volcanic plains. Based on similar values of slope estimated for large volcanoes and regional volcanic plains, we choose $0.5^{\bullet}$ for the edge angle of our cone approach of volcanic unit. This value of $0.5^{\circ}$ estimated from the large volcanic plains (Kreslavsky and Head,1999; Collins et al., 1999) is adequate considering that these large units are the most important during modeling for erasing and partially flooding craters.

A crater is erased when the thickness of a postdating volcanic unit in the same location exceeds the rim height. If the thickness of the volcanic flow does not exceed the rim height, the crater is marked as modified, and the remnant of the rim height is stored as the new rim height. When the edge of a volcanic unit is in contact with the ejecta surface of a crater it is also marked as a modified crater. At the end of each simulation we obtain the final number of craters, number of modified craters, frequency-size distribution of volcanic units and maps of the distribution of units and craters.

The randomness of the crater population is analyzed using the pair-correlation statistics following the procedure of Turcotte et al. (1999). The expected frequency distribution function for points uniformly randomly distributed over a sphere is

$f(l / a)=(1 / 2) \sin (l / a)$

where $a$ is the radius of the planet and I the length between craters measured on the sphere. Because of the very large number of pair-correlation data points obtained in each simulation the data are binned with bin width $\Delta l / a=0.05$. For each simulation the frequency distribution function $f(l / a)$ is calculated. We analyze the agreement between the analytical prediction of a uniformly random distribution (Eq. (2)) and the frequency distribution function of each model using the Pearson product moment correlation coefficient, $r$, which is a dimensionless index that ranges from -1 to 1 and reflects the extent of a linear relationship between two data sets.

The models were tuned by changing the total number of craters generated and total number of units generated in order to reproduce on average the number of craters on Venus, and number of observed volcanic units. As a result, from each model we get the number of modified craters and randomness of the crater population estimated by $r^{2}$. These results are then compared with the observations on Venus, testing the viability of each model. Considering that the models include random processes in space and time, each model is reproduced 250 times in order to obtain good statistics.

\section{Results}

The catastrophic evolution has been reproduced assuming that a catastrophic event completely regenerated the surface in the recent history of Venus ( $\sim 1 \mathrm{Gyr}$ ). Consequently, the catastrophic simulation starts with a surface free of craters immediately after the global resurfacing event; this surface is later partially covered by volcanic units and craters. Our catastrophic resurfacing model differs from previously proposed catastrophic evolutions (Schaber et al., 1992; Strom et al., 1994: Collins et al., 1999), where the volcanic activity after the global resurfacing event was very restricted. In our model a moderate volcanism covers $\approx 40 \%$ of the surface; thus we will name it a modified catastrophic model. At the end of the simulation, the number of craters on Venus is obtained, together with number of volcanic units observed.

Different exponential decays have been applied. On the one hand, if the exponential decay is very strong $(\kappa=5)$, the final distribution of craters is very close to completely random, but the number of modified craters is below the observations. On the other hand, when there is no decay of magmatic activity $(\kappa=0)$ the observed number of modified craters is reproduced but the spatial distribution of craters is far from a uniformly random distribution. Between these extremes, an intermediate decay rate $(\kappa=2)$ can reproduce both the randomness of the crater population and the number of modified craters. After the global resurfacing event, the surface is partially covered with an intermediate decay of volcanism $(\kappa=2$ ) by 17,000 volcanic units and 1200 impact craters; at the end of the simulation the observed number of craters on Venus (942) remain.

The duration of the equilibrium resurfacing model has to be larger than the modified catastrophic model, which implies the generation of a larger number of craters. In order to get at the end of the simulation the number of Venusian craters, the equilibrium steady-state resurfacing evolution requires a much larger number of volcanic units, covering several times almost the whole planetary surface. The equilibrium resurfacing simulation was performed by generating 150.000 volcanic units and 4300 craters; these parameters allow us to model the last $3.4 \mathrm{Gyr}$, obtaining at the end of the simulation the number of craters of Venus (942).

A true equilibrium model would imply a homogeneous magmatic rate with time, which means no exponential decay on the occurrence of volcanic units $(\kappa=0)$. These extreme models were performed, and the inevitable generations of medium and large units at the end of the model completely destroy the randomness of the crater population. A more realistic equilibrium evolution can be performed including a moderate decay of volcanism with time. A very strong exponential decay $(\kappa>4)$ is not compatible with equilibrium evolution because it implies unrealistically high magmatic rates in the early stages of Venus. This increase of magmatic rate is needed to maintain the observed number of craters at the end of the models. Nevertheless, a moderate decay $(\kappa=2)$ of the occurrence of volcanic units can reproduce the final number of craters with realistic magmatic rates. Consequently, the time distribution of volcanic events in the equilibrium model follows an exponential decay (Eq. (1)) with $\kappa=2$.

The age maps of typical modified catastrophic and equilibrium simulations are shown in Fig. $1 \mathrm{a}$ and b, respectively. Note that the equilibrium model shows a wider range in the ages of the volcanic plains. The locations of the craters are given in Fig. $1 \mathrm{c}$ for a modified catastrophic simulation and in Fig. 1d for an equilibrium simulation. Note the larger number of modified craters generated by the equilibrium resurfacing model. The modified craters of the catastrophic model are more abundant in the BAT anomaly area (Fig. 1c) due to the more frequent volcanism produced in that area, which is in very good agreement with the observations (Strom et al., 1994). Nevertheless, the modified craters of the equilibrium model are more abundant out of the BAT anomaly area (Fig. 1d), which is against the observation of real modified craters on Venus (Strom et al., 1994). This effect is generated because volcanic resurfacing in the equilibrium model is significantly more intense; consequently the equilibrium model erases efficiently most of the craters of the BAT anomaly, including the modified craters, leaving a relatively abundant population of modified craters out of the BAT anomaly.

The cumulative number of volcanic units versus area is shown in Fig. 2. The results for 250 modified catastrophic (Fig. 2a) and equilibrium (Fig. 2b) simulations can be compared with the Venusian frequency-area distribution of volcanic units measured on two zones of Venus representing $21 \%$ of the planetary surface (Romeo and Turcotte, 2009). The frequency-area distribution in the models was determined for the same two zones of Venus; therefore the edge problems are avoided. A portion of the BAT anomaly is included in one of the two zones; thus the percentages of area of the BAT anomaly analyzed on Venus and on the models are the same. For the modified catastrophic model, the largest 
a

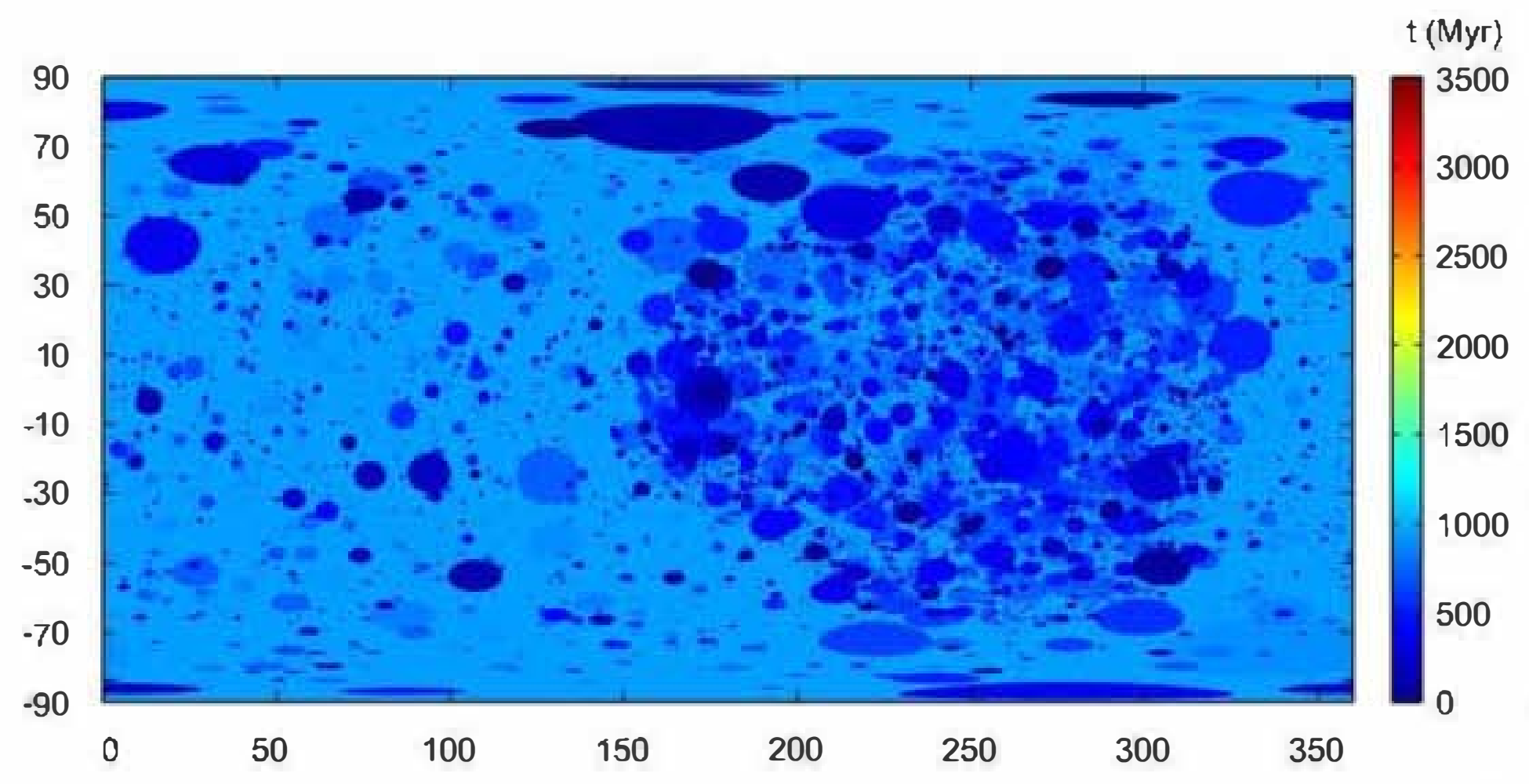

b

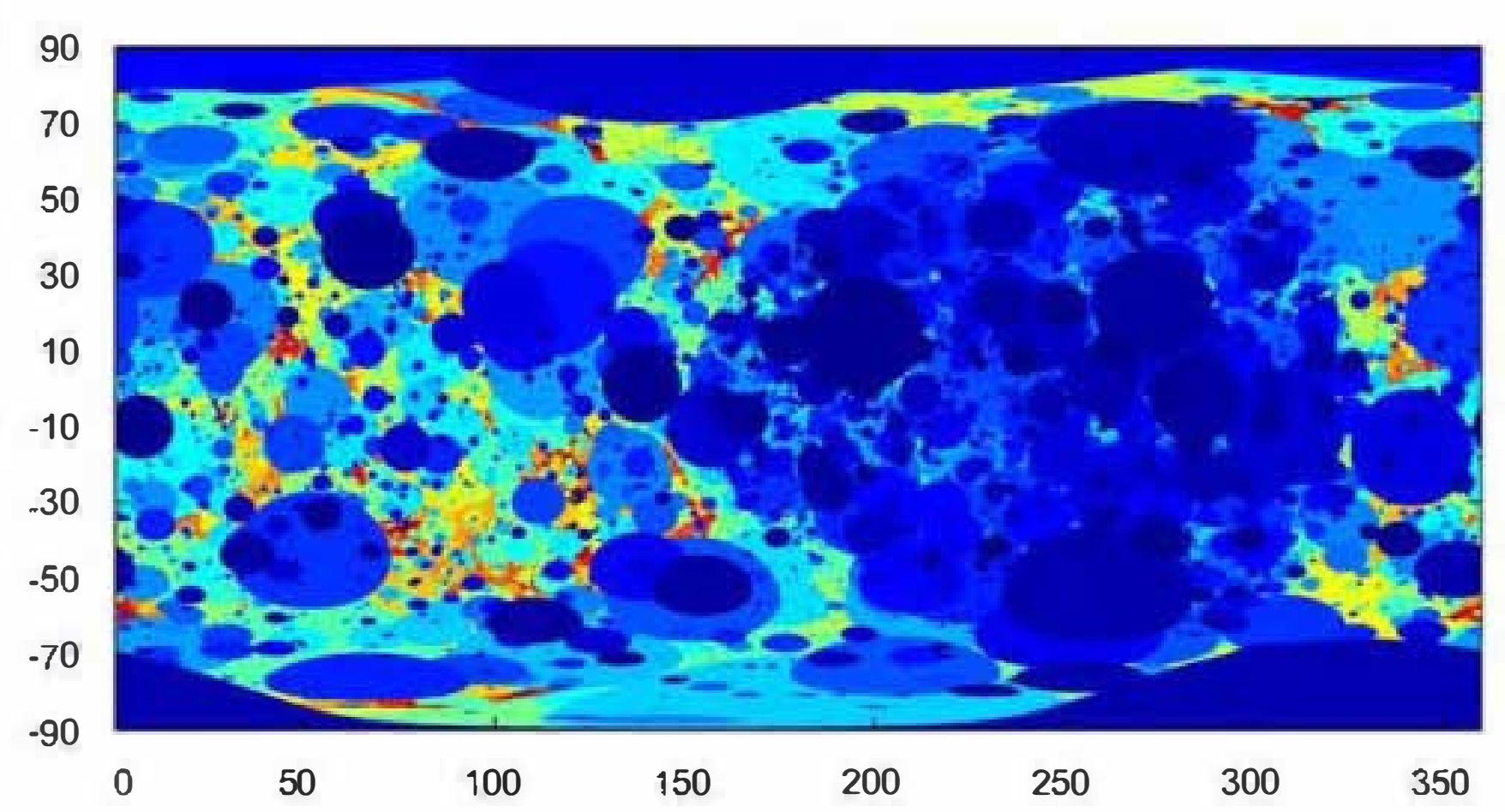

C

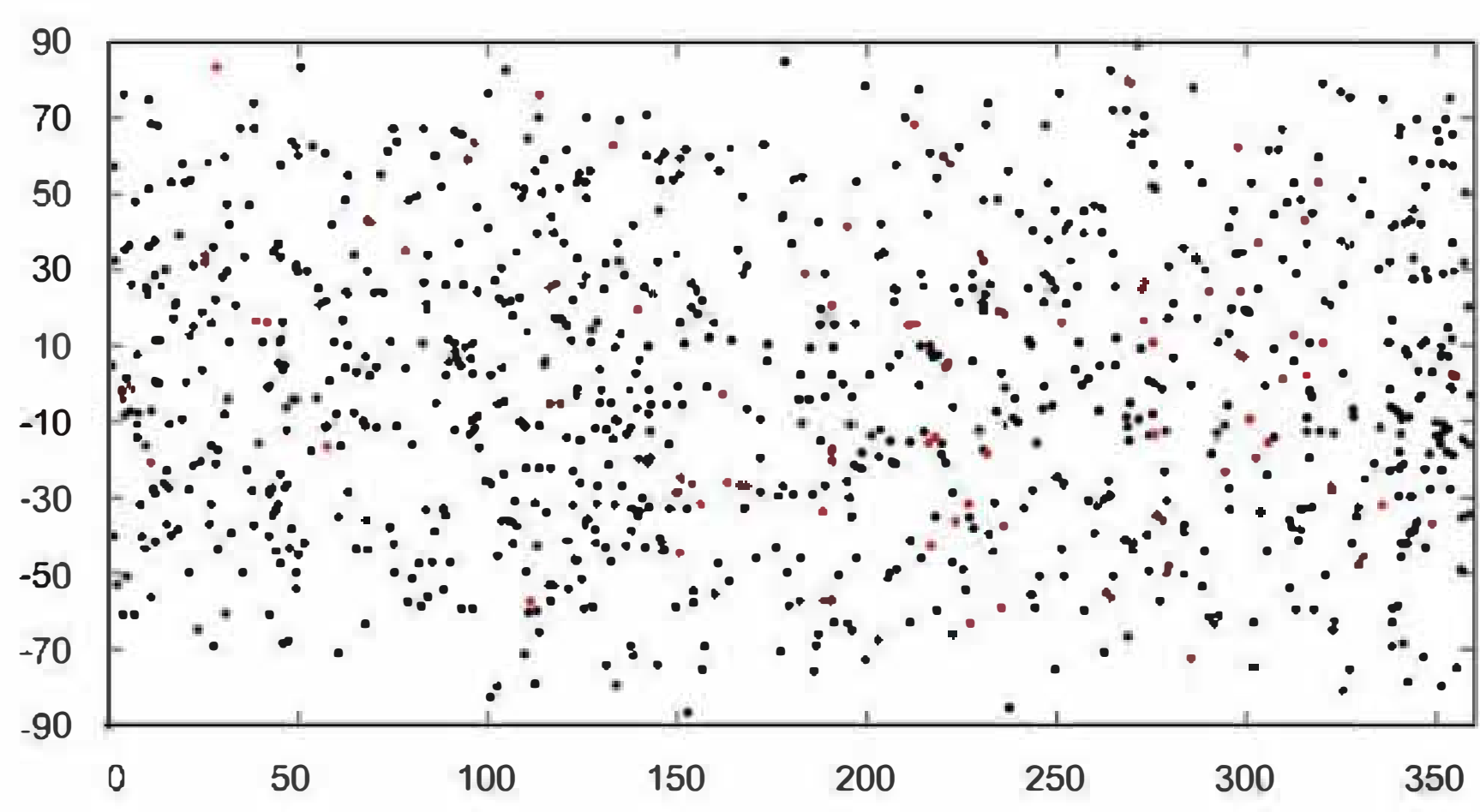

d

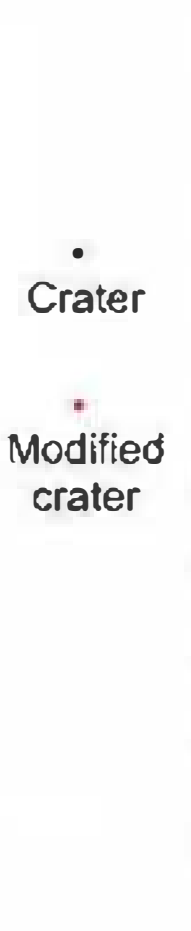

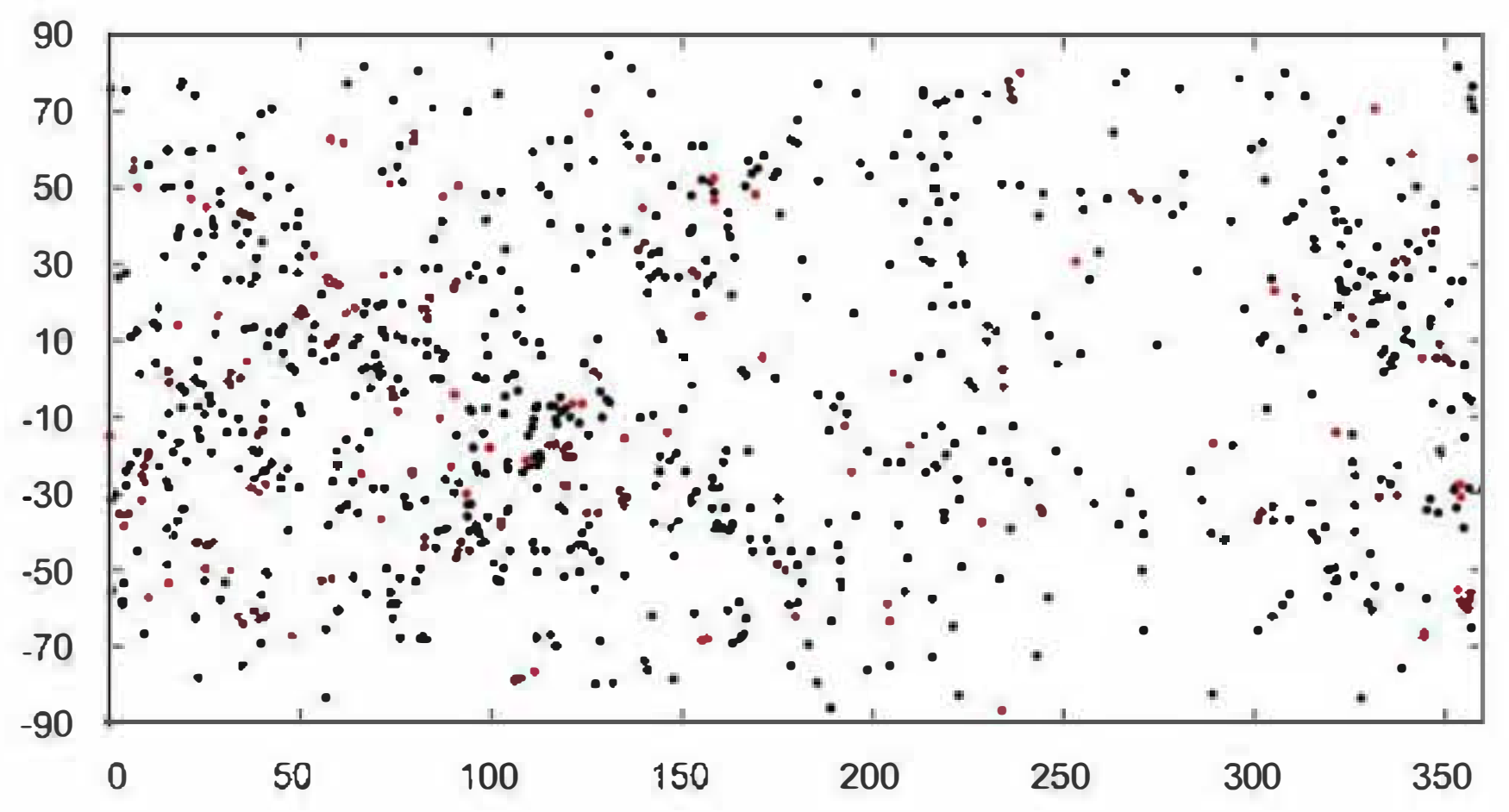

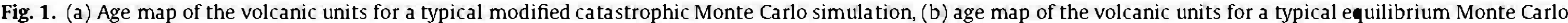

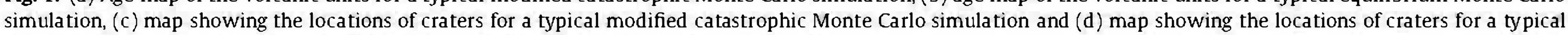
equilibrium Monte Carlo simulation. The locations of modified craters are also indicated.

unit in each of the two zones where the measurements were performed is interpreted to be the same unit (the largest point of the gray line on Fig. 2a). In the modified catastrophic model this unit is the original surface free of craters generated by the global resurfacing event. Contrary to the modified catastrophic model (Fig. 2a), in the analysis of equilibrium resurfacing (Fig. 2b) the largest unit of each of the two analyzed areas are not correlated to be the same unit with the same age; therefore these two units remain separated in the distribution (these are the two largest units of the Venusian distribution represented by the gray line in Fig. 2b).

In the catastrophic approach, only $\sim 40 \%$ of the surface is covered by new volcanic units; therefore the effect of overlapping units does not significantly change the frequency-area distribution. For this reason, using the Venusian frequency-area distribution without the two largest units (assumed in the catastrophic case to represent the basal plains generated in the last resurfacing event) the final frequency-area distribution measured in the models remains unchanged in the modified catastrophic simulation. But this is not the case for the equilibrium model. Equilibrium resurfacing implies a high rate of overlapping of volcanic units. When we use for the equilibrium the same frequency-area for the generation of units that we used in the modified catastrophic model (i.e. the Venusian frequencyarea of Romeo and Turcotte (2009) excluding the largest two units) the final results are very far from the Venusian frequencyarea distribution. In this case, the resultant frequency-area distribution has a final number of units more than twice the observed value, that is the result of filling $100 \%$ of the planetary surface with new volcanic units (instead of $40 \%$ of the modified catastrophic model). Therefore a modified frequency-area distribution needs to be introduced in the equilibrium simulation in order to get at the end a distribution similar to the observations, with the observed final number of volcanic units (1544 for the two studied areas). The first attempt in the search of a frequencyarea distribution that matches the observations was to use the complete observed frequency-area distribution, including the largest two units. This approach, although it can reproduce approximately the number of units and the shape of the frequency-area distribution, is not satisfactory. The presence of very large units produces crater populations very far from a uniformly random spatial distribution. Moreover, the largest units measured on the NASA-USGS maps could be considered to be formed by smaller units that have not been detected during radarbased geological mapping. A better approach to the equilibrium simulation can be performed by modifying the distribution used for the catastrophic model (i.e. the Venusian frequency-area excluding the two largest units) in order to get the observed number of units. The modified distribution used for the equilibrium model is represented by the dotted gray line in Fig. 2b. This distribution reproduces an acceptable final number of units (1403-2531) without the generation of very large units.

In Fig. 3 we show the evolution of magmatic rate with time. The magmatic rates for modified catastrophic resurfacing (Fig. 3a) fall from 30 to $2 \mathrm{~km}^{3} / \mathrm{yr}$, which indicates a moderate rate of magmatic activity after the global resurfacing event. The final rate of volcanism generated by the models is in good agreement with the estimations of $1-4 \mathrm{~km}^{3} / \mathrm{yr}$ for the actual volcanic rate on Venus (Fegley and Prinn, 1989; Mian and Tozer, 1990; Stofan et al., 2005). On the other hand, Fig. 3b shows the magmatic rates for equilibrium resurfacing ranging from 260 to $40 \mathrm{~km}^{3} / \mathrm{yr}$.

The pair-correlation statistics of the crater population are given in Fig. 4. The modified catastrophic resurfacing (Fig. 4a) is 

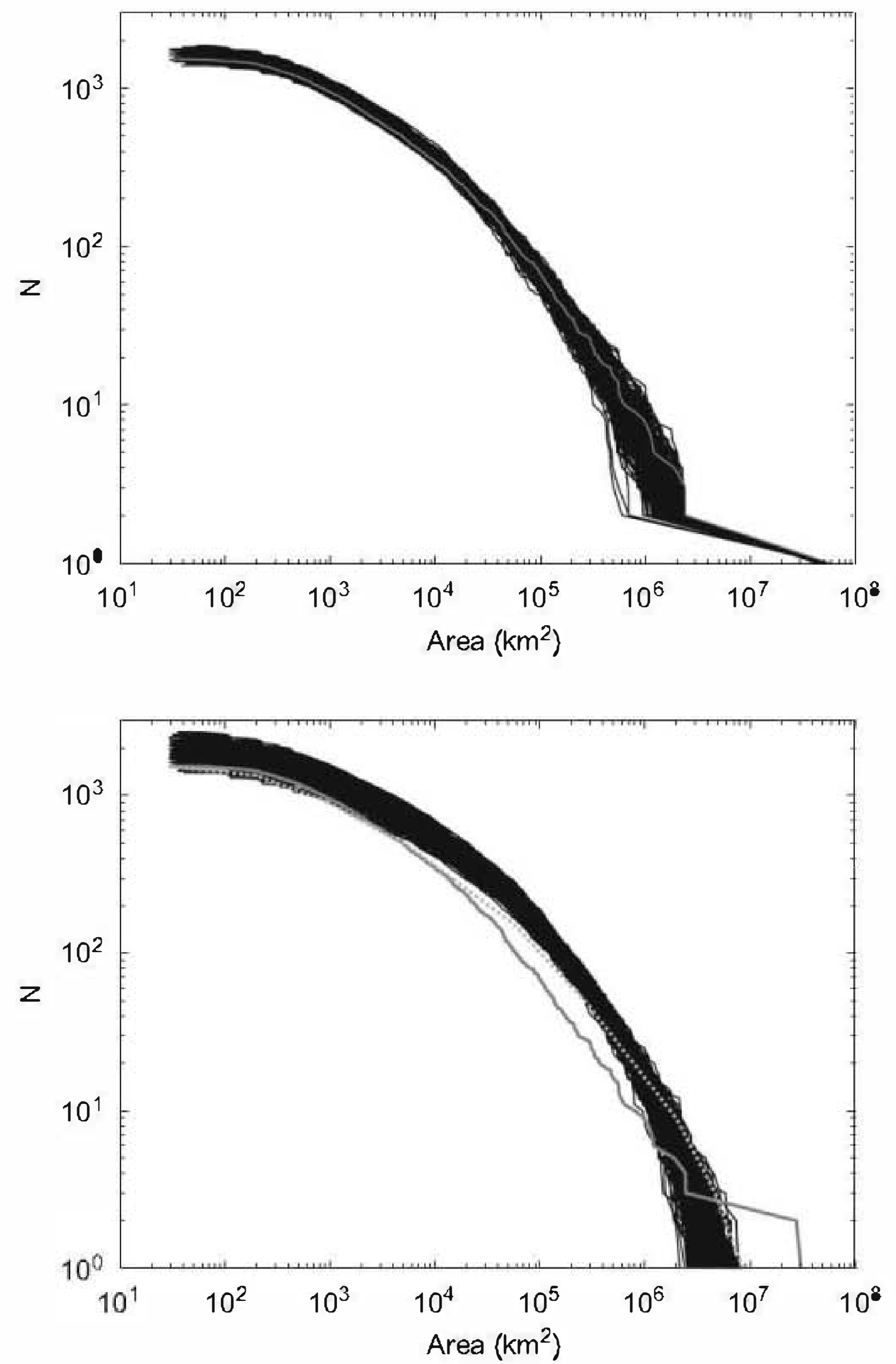

Fig. 2. Cumulative number of volcanic units given as a function of area. (a) Modified catastrophic resurfacing and (b) equilibrium resurfacing. The black lines represent the results of 250 Monte Carlo simulations, the gray line represents the frequency-area distribution of Venus and the dotted gray line is the frequency-area distribution used in the equilibrium resurfacing simulations.

well correlated with the distribution expected for uniformly random points on a sphere indicated by the gray line. The frequency of pair distances for equilibrium resurfacing (Fig. 4b) is significantly different from that of a uniformly random distribution. The value $r$ for each model has been calculated, and the cumulative distribution function of $r^{2}$ is given in Fig. 5a. It can be compared with the value $r^{2}=0.9988$ for the 942 Venusian craters, whose locations were obtained from the updated version, third release, of the crater database of Herrick et al., (1997), and can also be compared with the cumulative distribution function of 250 simulations of 942 points randomly placed on a sphere. The value of $r^{2}$ for Venus is located among the values of the random distribution, which indicates that the Venusian crater population is indistinguishable from a random distribution, a fact shown by Schaber et al. (1992) and Phillips et al. (1992). The pair-correlation statistics do not reject randomness for the modified catastrophic model, while it rejects randomness for the equilibrium model. The equilibrium resurfacing model cannot reproduce the values of $r^{2}$ observed on Venus.

The cumulative distribution function of the number of modified craters is plotted in Fig. 5b. The modified catastrophic

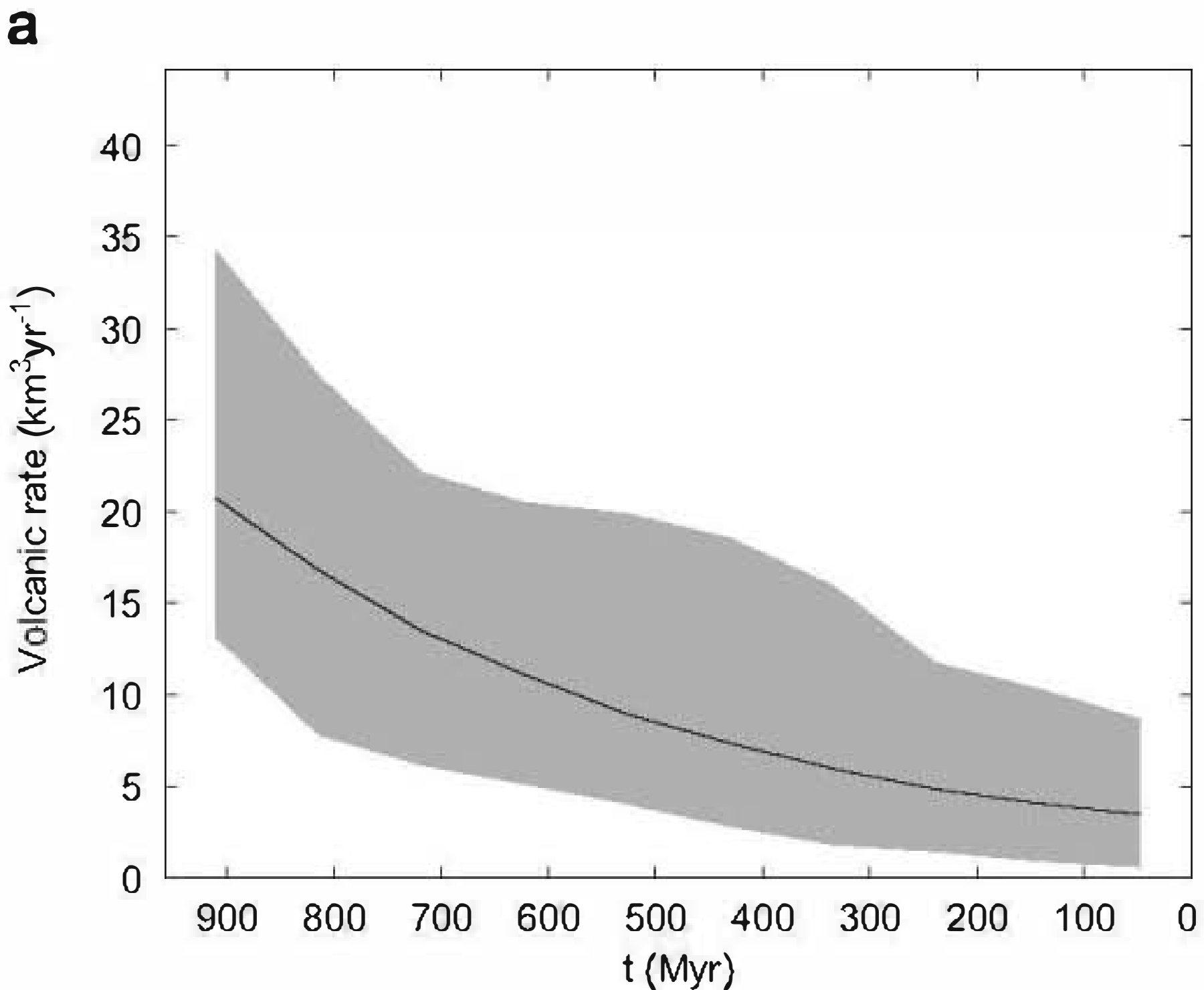

b

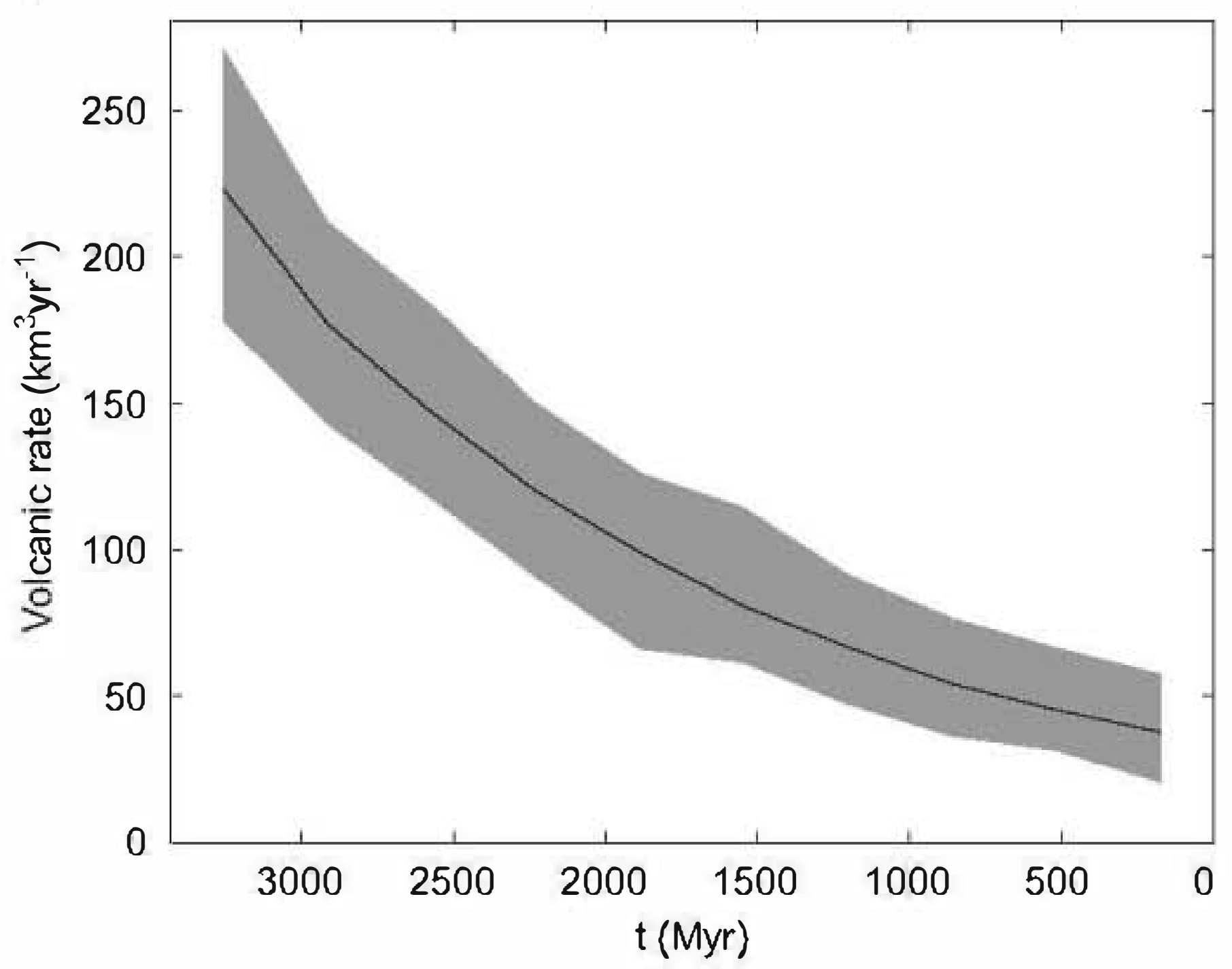

Fig. 3. Evolution of the magmatic rate $\left(\mathrm{km}^{3} / \mathrm{yr}\right)$ with time for 250 Monte Carlo simulations of (a) modified catastrophic resurfacing and (b) equilibrium resurfacing. Shaded area represents stochastic variations between different individual models, and the black line is the average.

evolution model produces modified craters in the range 54-99 $(75.78 \pm 15.75,2 \sigma$ uncertainties). The equilibrium resurfacing produces modified craters in the range 90-182 (140.5 $\pm 30.38,2 \sigma$ uncertainties). Both results are in good agreement with the estimates of the number of modified craters of Venus provided by Herrick et al. (1997) and Herrick and Sharpton (2000), 85-129, and Wichman (1999), 57-123. The equilibrium resurfacing is in contradiction with the very low number of modified craters estimated by Schaber et al. (1992), 56 and Collins et al. (1999), 29-56.

The magmatism generated after the global resurfacing event in our catastrophic simulation covers $40 \%$ of the planetary surface. This value is imposed by the observation that $40 \%$ of the area is covered by young units in the study of the frequency-area distribution performed by Romeo and Turcotte (2009). This moderate magmatic activity can account for the higher number of modified craters estimated by Herrick and Sharpton (2000) and Wichman (1999). Therefore, our catastrophic model is quite different from the proposed catastrophic evolution of Strom et al. (1994), where only $4-6 \%$ of the planet has been volcanically resurfaced since the last global resurfacing event. 
a

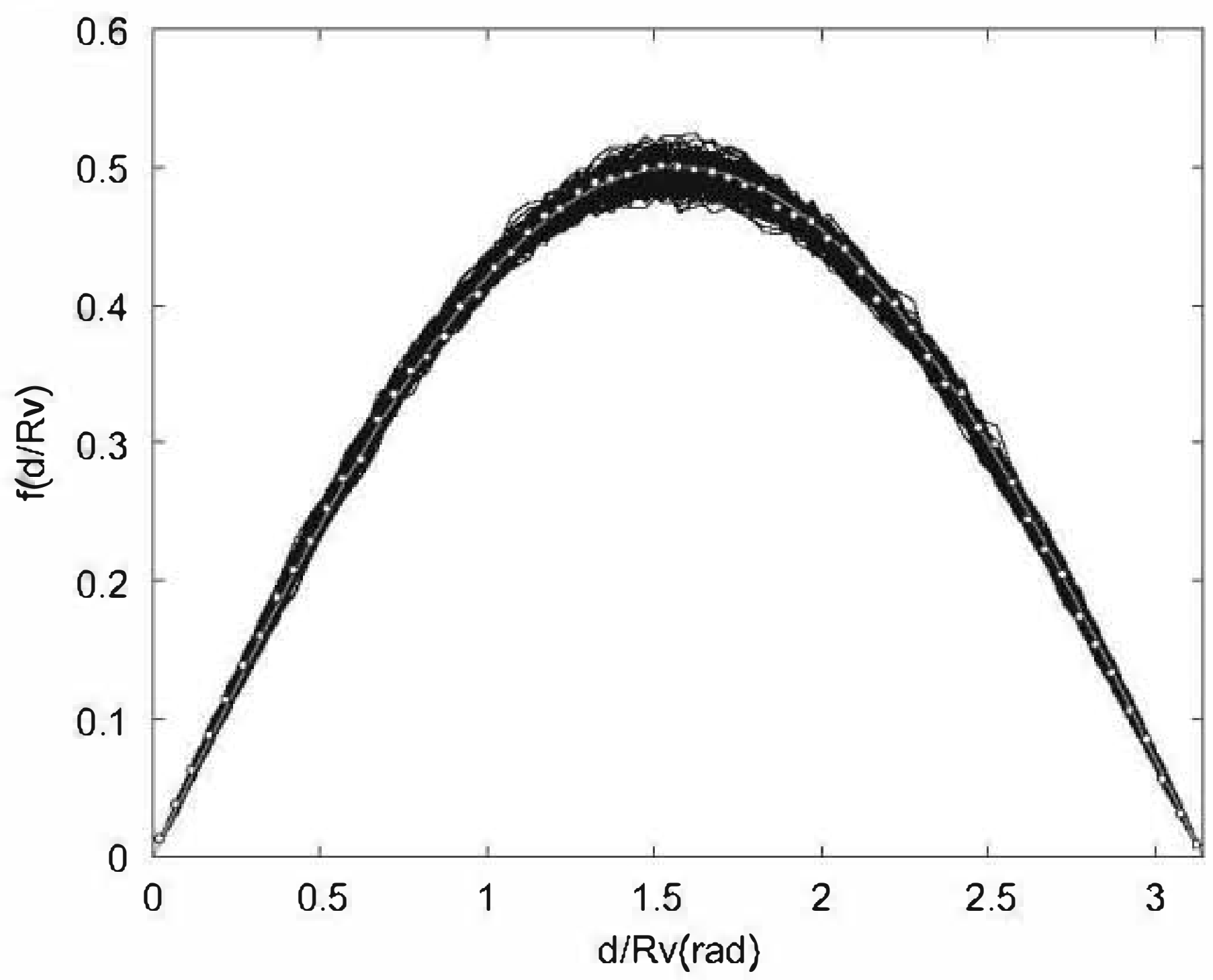

b

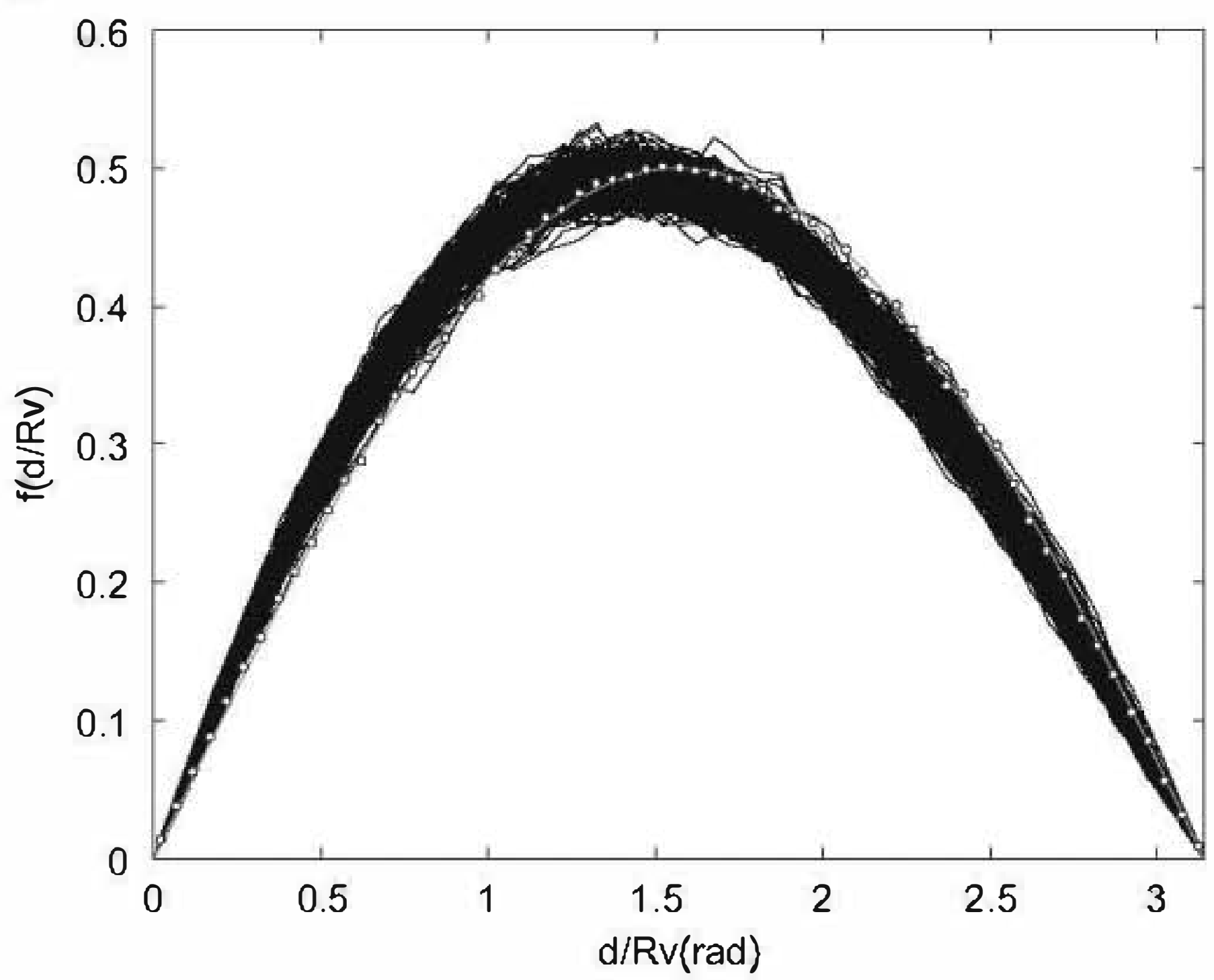

Fig. 4. Pair-correlation statistics of the crater population for 250 Monte Carlo simulations of (a) modified catastrophic resurfacing and (b) equilibrium resurfacing is shown by black lines. The gray line is the analytical solution for a uniformly random distribution of points on a sphere. The white points represents actual Venus crater distribution.

\section{Conclusions}

We have applied the observed frequency-area distribution of volcanic units on Venus, together with a detailed simulation of the relation between resurfacing and cratering using a 3D approach for cratering modification, in Monte Carlo resurfacing models. Our results indicate that the size of individual volcanic units on Venus is too large to be compatible with an equilibrium steady-state resurfacing of the planet, because the generation of these units produces holes in the crater distribution breaking the observed randomness of the crater population. However, the observed randomness of the crater population together with the number of modified craters can be achieved by a modified catastrophic evolution where a global resurfacing event took place $\approx 1 \mathrm{Gyr}$ ago (if the average age is $750 \mathrm{Myr}$, McKinnon, et al. 1997).

This result is robust, considering that when modeling the equilibrium evolution we have limited the size of the volcanic a

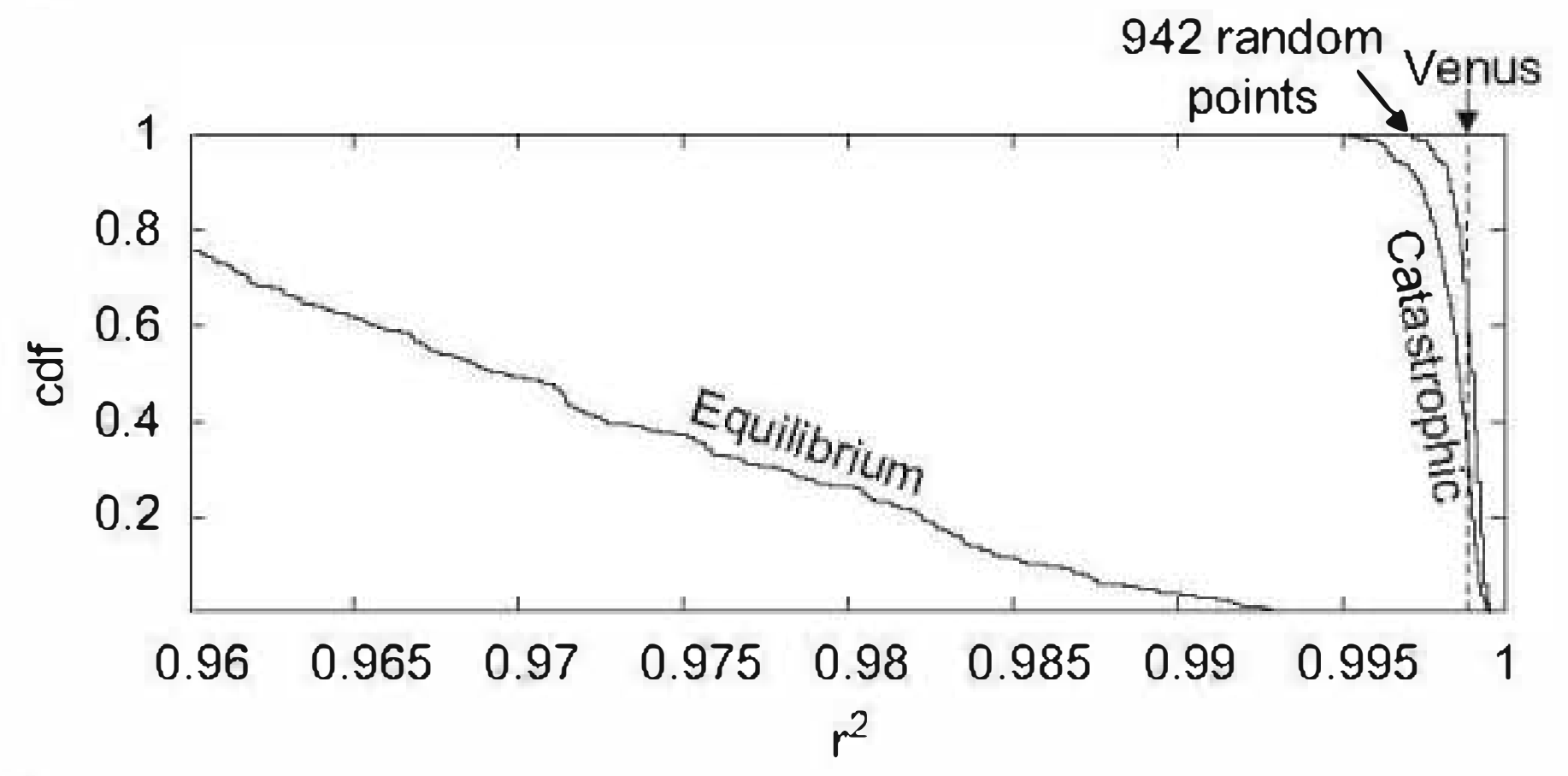

b

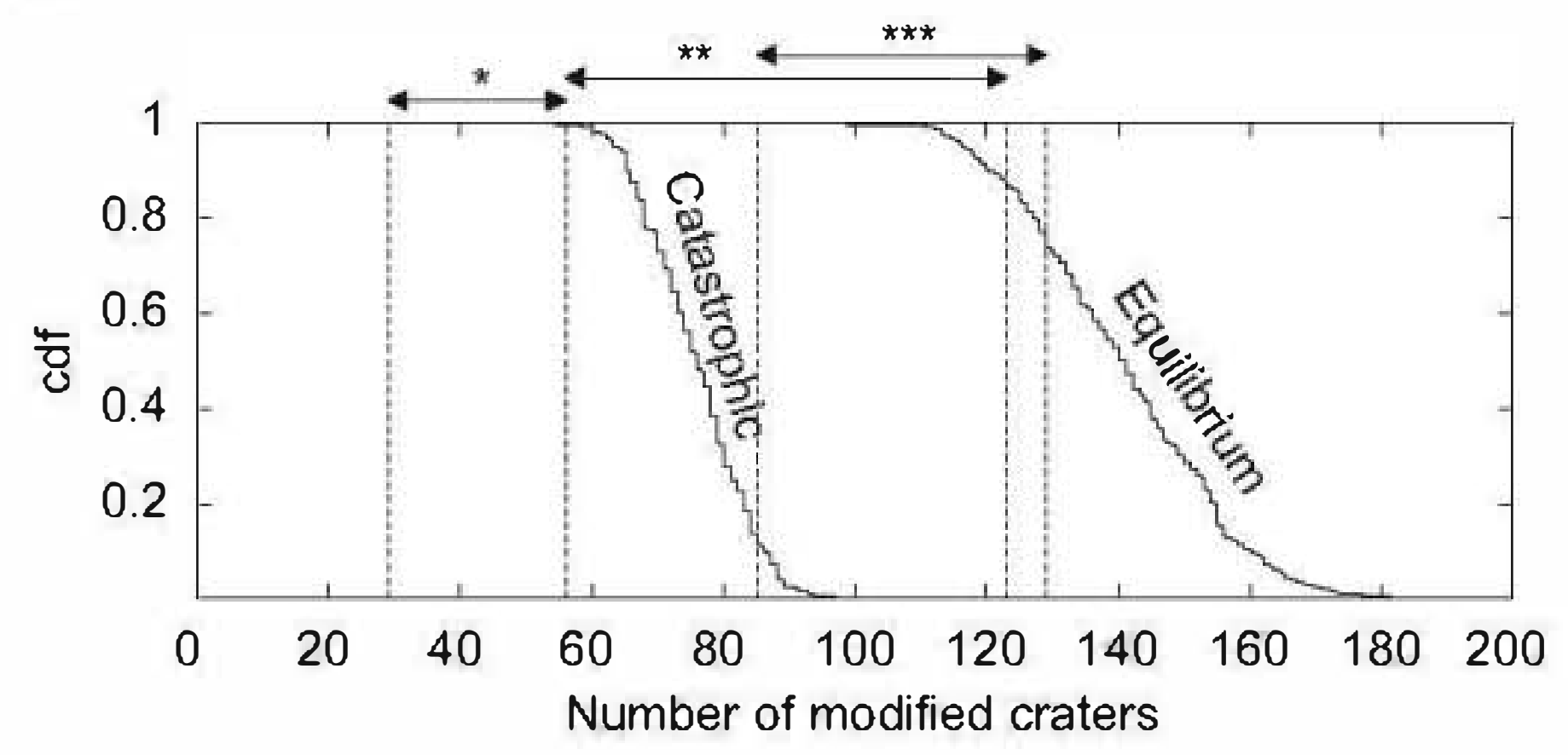

Fig. 5. (a) Cumulative distribution functions of the values of $r^{2}$ ( $r=$ Pearson product moment correlation coefficient) of 250 Monte Carlo simulations for modified catastrophic and equilibrium resurfacing. The values of $r^{2}$ calculated for Venus and the cumulative distribution function of 250 simulations of 942 points uniformly and randomly placed on a sphere are shown for comparison. (b) Cumulative distribution functions of the number of modified craters from 250 Monte Carlo simulations of both the modified catastrophic and equilibrium resurfacing. Estimations of the number of craters modified by volcanism on Venus by ${ }^{*}$ Collins et al. (1999), ${ }^{* *}$ third release updated database of Herrick et al. (1997), and ${ }^{* * *}$ Wichman (1999) are shown for comparison.

units as much as possible, considering the possibility that the large basal units of the volcanic plains observed in the NASA-USGS $1: 5,000,000$ geological maps could be formed by different smaller units that cannot be observed in the radar images (see difference between the largest Venusian units and the largest units of the models in Fig. 2b). Even with these special considerations an equilibrium evolution cannot maintain the randomness of the crater population. Not only are the large units of the volcanic plains incompatible with equilibrium resurfacing, but the largest units generated by volcanoes and corona, which were used in our model, are also incompatible with equilibrium resurfacing. This is caused by the fact that these units generated with different ages are incompatible with the randomness of the crater population.

The distribution of modified craters in the models is controlled by the presence of the BAT anomaly. Modified catastrophic resurfacing is in good agreement with the concentration of modified craters observed in the BAT anomaly area, while equilibrium resurfacing produces more modified craters out of the BAT anomaly. The larger numbers of craters modified by volcanic flooding found by Wichman (1999) and Herrick and Sharpton (2000) can be produced by a moderate volcanism covering $40 \%$ of the planetary surface from the last global resurfacing event following a moderated decay of the volcanic activity. Therefore, our catastrophic resurfacing model differs from previously proposed catastrophic evolutions (Schaber et al., 1992; Strom et al., 1994; Collins et al., 1999), where the volcanic activity after the global resurfacing event was very restricted.

The global resurfacing event calls for a geodynamical explanation (Parmentier and Hess, 1992; Head et al., 1994; Moresi and 
Solomatov, 1998; Reese et al.,1999). The hypothesis of global episodic subduction events as a mechanism for cooling Venus proposed by Turcotte $(1993,1995,1996)$ and Turcotte et al. (1999) provides a simple explanation. It also explains why the large basal volcanic units where emplaced over a surface almost free of craters, a fact shown by Collins et al. (1999) and can account for the tectonic evolution of the tessera terrains if those terrains were made up of differentiated crust that do not participate in the subduction events (Romeo and Turcotte, 2008). The recent catastrophic evolution of Venus indicates that the geodynamical mechanisms for cooling a planet can be very different than the steady-state resurfacing of plate tectonics on Earth.

\section{Acknowledgments}

This research was supported by a Fulbright-Spanish Ministry of Education postdoctoral grant. Commentaries from A.T. Basilevsky and E.R. Stofan improved this contribution. We would like to specially thank the accurate review performed by M.A. Kreslavsky.

\section{References}

Bjonnes, E.E., Hansen, V.L., Swenson, J.B., 2008. Results of equilibrium resurfacing Monte Carlo models on Venus. In: Proceedings of the 39th LPSC, \#2410.

Bender, K.C., Senske, D.A., Greeley, R, 2000. Geologic map of the Carson quadrangle (V-43), Venus. USGS Geologic Investigations Series I-2620.

Bond, T.M., Warner, M.R, 2006. Dating Venus: statistical models of magmatic activity and impact cratering. In: Proceedings of the 37th LPSC, \#1957.

Bullock, M.A., Grinspoon, D.H., Head, J.W., 1993. Venus resurfacing rates: constraints provided by 3-D Monte Carlo simulations. Geophysical Research Letters 20, 2147-2152.

Campbell, B.A., Campbell, P.G., 2002. Geologic map of the Bell Regio quadrangle (V-9), Venus. USGS Geologic Investigations Series I-2743.

Campbell, B.A., Clark, D.A., 2006. Geologic map of the Mead quadrangle (V-21), Venus. USGS Scientific Investigations I-2897.

Collins, G.C., Head, J.W., Basilevsky, A.T., Ivanov, M.A., 1999. Evidence for rapid regional plains emplacement on Venus from the population of volcanically embayed impact craters. Journal of Geophysical Research 104 (E10), 24121-24139

Copp, D.L., Guest, J.E., 2007. Geologic map of the Sif Mons quadrangle (V-31), Venus. USGS Scientifiic Investigations I-2898.

Crumpler, L.S., Aubele, J.C., Senske, D.A., Keddie, S.T., Magee, K.P., Head, J.W., 1997. Volcanoes and centers of volcanism on Venus. In: Bougher, W., Hunten, D.M. Phillips, R.J. (Eds.), Venus II. University of Arizona Press, Tucson, pp. 697-756.

Fegley, B., Prinn, R, 1989. Estimation of the rate of volcanism on Venus from reaction rate measurements. Nature 337 (6202), 55-58.

Hansen, V.L., DeShon, H.R, 2003. Geologic map of the Diana Chasma quadrangle (V-37), Venus. USGS Geologic Investigations Series I-2752.

Hauck, S.A., Phillips, RJ., Price, M.H., 1998. Venus; crater distribution and plains resurfacing models. Journal of Geophysical Research 103 (E6), 13635-13642.

Head, J.W., Crumpler, L.S., Aubele, J.C., 1992. Venus volcanism: classification of volcanic features and stuctures, associations, and global distribution from Magellan Data. Journal of Geophysical research 97, 13153-13197.

Head, J.W., Parmentier, E.M., Hess, P.C., 1994. Venus: vertical accretion of crust and depleted mantle and implications for geological history and processes. Planetary and Space Science 42, 803-811.

Herrick, RR, Sharpton, V.L., Malin, M.C., Lyons, S.N., Feely, K., 1997. Morphology and morphometry of impact craters. In: Bougher, W., Hunten, D.M., Phillips,
R.J. (Eds.), Venus II. University of Arizona Press, Tucson, pp. 1015-1046 updated database available at.

Herrick, RR, Sharpton, V.L, 2000. Implications from stereo-derived topography of Venusian impact craters. Journal of Geophysical Research 105 (E8) 20245-20262.

Herrick, RR, Dufek,J., McGovern, P.J., 2005. Evolution of large shield volcanoes on Venus. Journal of Geophysical Research 110, E01002.

Ivanov, M.A., Head, J.W., 2004. Geologic map of the Atalanta Planitia quadrangle (V-4), Venus. USGS Geologic Investigations Series I-2792

Ivanov, M.A., Head, J.W., 2005. Geologic map of the Nemesis Tesserae quadrangle (V-13), Venus. USGS Scientific Investigations I-2870.

Kresla vsky, M.A., 1996. Venus cratering record: constraints on resurfacing history Lunar and Planetary Science 27, 697-698.

Kreslavsky, M.A., Head, J.W., 1999. Morphometry of small sheild volcanoes on Venus: implications for the thickness of regional plains. Journal of Geophysical Research 104 (E8), 18925-18932.

McGill, G.E., 2004. Geologic map of the Bereghinya Planitia quadrangle (V-8) Venus. USGS Geologic Investigations Series I-2794.

McGill, G.E., 2000. Geologic map of the Sappho Patera quadrangle (V-20), Venus USGS Geologic Investigations Series I-2637.

McKinnon, W.B., Zahnle, K., Ivanov, B.A., Melosh, H.J., 1997. Cratering on Venus: modeling and observations. In: Bougher, W., Hunten, D.M., Phillips, RJ. (Eds.) Venus II. University of Arizona Press, Tucson, pp. 969-1014.

Mian, Z.U., Tozer, D.C., 1990. No water, no plate tectonics; convective heat transfer and the planetary surfaces of Venus and Earth. Terra Nova 2 $455-459$.

Moresi, L., Solomatov, V., 1998. Mantle convection with a brittle lithosphere thoughts on the global tectonic styles of the Earth and Venus. Geophysical Journal International 133, 669-682.

Parmentier, E.M., Hess, P.C. 1992. Chemical differentiation of a convecting planetary interior consequences for a one plate planet such as Venus. Geophysical Research Letters 19, 2015-2018.

Phillips, RJ., Raubertas, R.F., Arvidson, RE., Sarkar, I.C., Herrick, R.R, Izenberg, N., Grimm, RE., 1992. Impact craters and Venus resurfacing history. Journal of Geophysical Research 97, 15923-15948.

Reese, C.C., Solomatov, V.S., Moresi, L.-N., 1999. Non-Newtonian stagnant lid convection and magmatic resurfacing on Venus. Icarus 139, 67-80.

Romeo, I., Turcotte, D., 2008. Pulsating continents on Venus: an explanation for crustal plateaus and Tessera terrains. Earth and Planetary Science Letters 276 85-97.

Romeo, I., Turcotte, D., 2009. The frequency-area distribution of volcanic units on Venus: implications for planetary resurfacing. Icarus 203, 13-19.

Rosenberg, E., McGill, G.E., 2001. Geologic map of the Pandrosos Dorsa quadrangle (V-5), Venus. USGS Geologic Investigations Series I-2721.

Schaber, G.G., Strom, RG., Moore, H.J., Soderblom, L.A., Kirk, R.L, Dawson, D.J. Gaddis, L.R, Boyce, J.M., Russell, J., 1992. Geology and distribution of impac craters on Venus: what are they telling us? Journal of Geophysical Research 97 13256-13301.

Stofan, E.R, Brian, A.W., Guest, J.E., 2005. Resurfacing styles and rates on Venus: assessment of 18 venusian quadrangles. Icarus 173, 312-32.1.

Strom, RG., Schaber, G.G., Dawson, D.D., 1994. The global resurfacing of Venus Journal Geophysical Research 99 (E5), 10899-10926.

Turcotte, D.L., 1993. An episodic hypothesis for Venusian tectonics. Journal of Geophysical Research 98, 17061-17068.

Turcotte, D.L., 1995. How does Venus lose heat? Journal of Geophysical Research $10016931-16940$.

Turcotte, D.L, 1996. Magellan and comparative planetology. Journal of Geophysical Research 101, 4765-4773.

Turcotte, D.L., Morein, G., Roberts, D., Malamud, B.D., 1999. Catastrophic resufacing and episodic subduction on Venus. Icarus 139, 49-54

Wichman, RW., 1999. Internal crater modification on Venus: recognizing cratercentered volcanism by changes in floor morphometry and floor brightness. Journal of Geophysical Research 104 (E9), 21,957-21,977.

Young, D.A., Hansen, V.L., 2003. Geologic map of the Rusalka Planitia quadrangle (V-25), Venus. USGS Geologic Investigations Series I-2783. 